\title{
Seismic amplitudes and spectral attribute analysis in reservoir characterisation, 'MUN' onshore Niger delta field
}

\author{
J. M. Munyithya ${ }^{1,3}$ (1) C. N. Ehirim² ${ }^{2}$ T. Dagogo² $\cdot$ M. O. K'orowe ${ }^{3}$
}

Received: 28 August 2019 / Accepted: 25 May 2020 / Published online: 9 June 2020

(c) The Author(s) 2020

\begin{abstract}
Integrating seismic amplitudes and spectral attribute analysis has successfully mapped, validated and characterised hydrocarbon-saturated channel sands by high-amplitude low-frequency anomaly. The aim of the study was targeted at using these novel geophysical tools to improve characterisation of tertiary clastic reservoir in the field. These attributes were extracted along $\mathrm{H} 4$ seismic horizon and analysed independently for structure, lithology and hydrocarbon saturation. The result of the analysis shows that both attributes complimented each other in mapping the hydrocarbon-saturated reservoir channel sands. However, the spectral attributes in combination with spectral-based Red, Blue and Green (RGB) colour blending attribute map reveal finer and subtle details of the channel structure and stratigraphy which hitherto were not apparent in the seismic amplitude maps. The channel sands trend NE-SW, broadening towards the southwest and bounded by major growth faults to the northeast and southwest, respectively. It is thick to the southwest and thins to the northeast. By-passed hydrocarbon prospect was delineated to the northeast of the existing wells, and as such, infill wells can be drilled in these areas to recover hydrocarbons.
\end{abstract}

Keywords Seismic amplitude $\cdot$ Spectral attribute $\cdot$ Sweetness $\cdot$ Channel sand $\cdot$ RGB

\section{Introduction}

Reservoir characterisation is fundamental in assessing the prospectivity and economics of a given hydrocarbon reservoir. Characterisation entails identifying, mapping and estimating petrophysical, structural, stratigraphic and geometric reservoir properties for effective development and exploitation of hydrocarbons from well and seismic data.

\footnotetext{
J. M. Munyithya

jmmunyithya@jkuat.ac.ke

C. N. Ehirim

ehirimcn@yahoo.com

T. Dagogo

nengi.dagogo@uniport.edu.ng

M. O. K'orowe

modondi@yahoo.com

1 World Bank, ACEFOR, University of Port Harcourt, Port Harcourt, Nigeria

2 Physics Department, UNIPORT, Box 122, Choba, Port Harcourt, Nigeria

3 Physics Department, JKUAT, Box 62000, Nairobi, Kenya
}

However, this process is complicated by the quality of data, geology and interpretational methods adopted in analysing data. These results in the prediction of error-bound reservoir properties, leading to the drilling of less performing or dry wells and subsequently, poor returns on investment.

Previous studies have independently demonstrated the effectiveness of seismic reflection amplitudes and spectral attribute analysis as direct hydrocarbon indicators (DHI), mapping of stratigraphic units and structures and evaluation of reservoir properties (Partyka et al. 1999; Marfurt and Kirlin 2001; Othman et al. 2016; Ehirim and Akpan 2017). However, seismic amplitude is encumbered by ambiguity due to acquisition footprints, processing and imaging errors, surface conditions and geologic factors, which can lead to amplitude interpretation pitfalls during reservoir characterisation if not validated (Houk 1999; Harilal 2010).

Validation of amplitude interpretation can be done using AVO, shear wave or a character of the reflection event such as frequency. This ensures that amplitude-related anomalies are interpreted with certainty and reservoirs delineated and well characterised. Therefore, integrating seismic amplitudes and spectral attributes in characterising the reservoir 
will enhance the confidence of interpretation and drilling of more successful wells.

Seismic amplitude extracted from the seismic reflection data is a measure of the reflection strength governed by the contrast in elastic properties across the geologic interface. The amplitude response of a reflection event across a geologic interface depends on the pore geometry, saturation and pore fluid type, lithology, pressure and depth of burial (Hilteman 2001). Amplitude brightening related to the presence of hydrocarbons, especially gas sands in unconsolidated tertiary clastics have been reported by some authors (Hart 2008; Okoch and Atakpo 2017). Also, due to its characteristic relationship with reservoir properties particularly porosity, saturation and lithology, seismic amplitude has become the most used attribute in reservoir characterisation.

Frequency or spectral attributes are generated through spectral decomposition of seismic data in time into individual frequency attributes. This way, the same subsurface geology can be tuned and viewed in different frequencies in other to determine the optimum frequency attribute that adequately and efficiently images and characterises the reservoir (Ahmad and Rowell 2012; Chopra and Marfurt 2013; Wei et al. 2019). The reflection amplitude is a function of frequency in fluid-saturated media. Hydrocarbons produce a brightening effect (high amplitude) on a low-frequency section characteristic of a porous and thick hydrocarbonsaturated reservoir (Ehirim and Akpan 2017).
The present study is therefore aimed at integrating seismic amplitude attributes (Envelop, RMS and Sweetness) and spectral (frequency) attributes for improved reservoir characterisation, field planning and development in MUN onshore Niger delta field.

MUN onshore Niger delta field is located in the coastal swamp depobelt of the Niger delta (Fig. 1). The Niger delta is one of the world's largest hydrocarbon provinces situated on the Gulf of Guinea and extends through the Niger delta provinces (Klett et al. 1978). The swamp depobelt is characterised by rain forest and mangrove vegetation cover, and landscape incised by numerous brackish rivulets and creeks that flows into the Atlantic Ocean.

\section{Geology of the study area}

The Niger delta is composed of regressive clastic sedimentary sequence of Tertiary age (Evamy et al. 1978). The delta has prograded overtime southwards, forming depobelts that represent the most active portion of the delta at each stage of its development (Fig. 2). These depobelts coalesced and form one of the largest regressive deltas in the world with an area of about $300,000 \mathrm{~km}^{2}$, a sediment volume of about $500,000 \mathrm{~m}^{3}$ and a sediment thickness of over $10 \mathrm{~km}$ in the basin depocenter (Doust and Omatsola 1990).

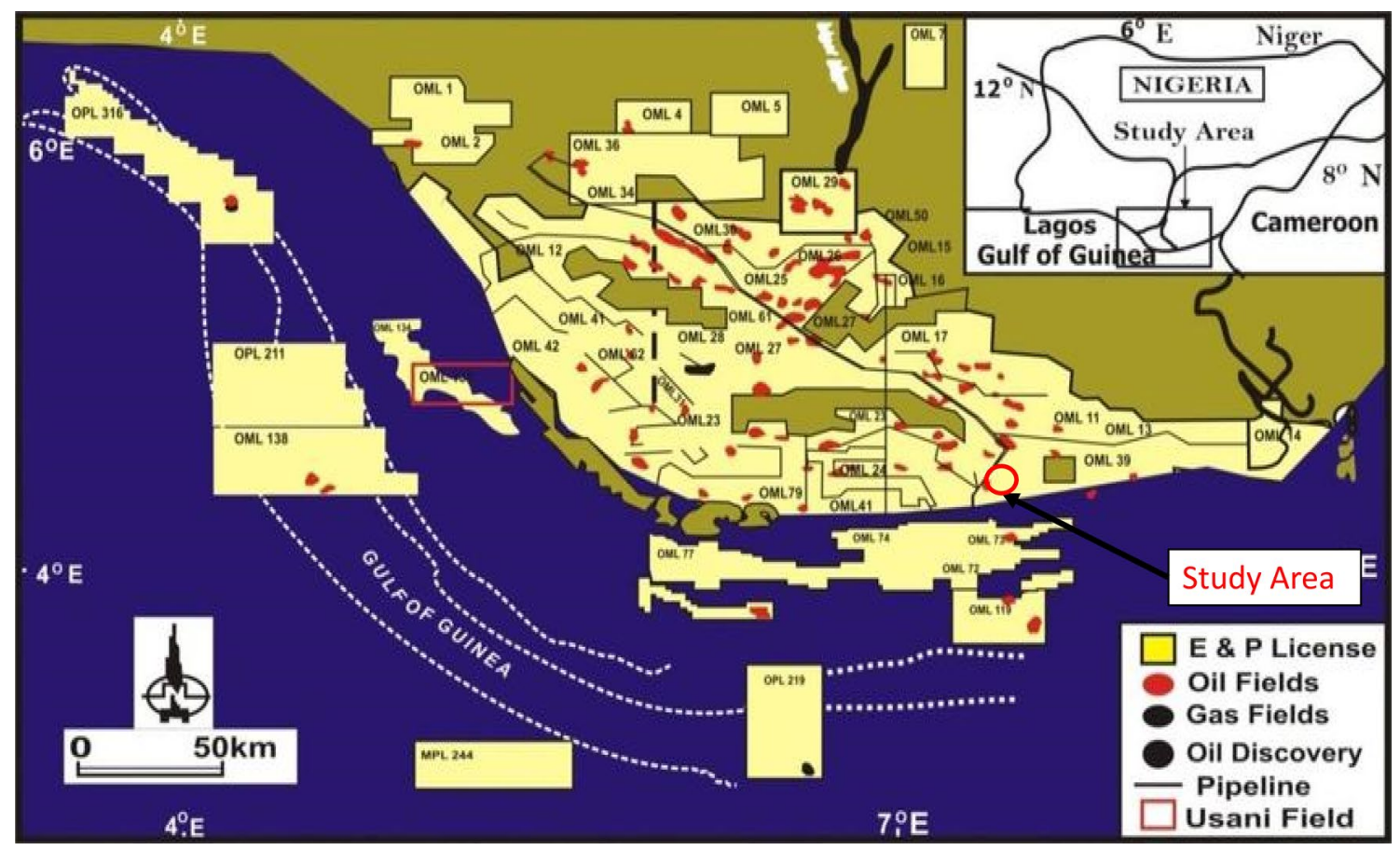

Fig. 1 Location map of the study area (Aigbadon et al. 2017) 


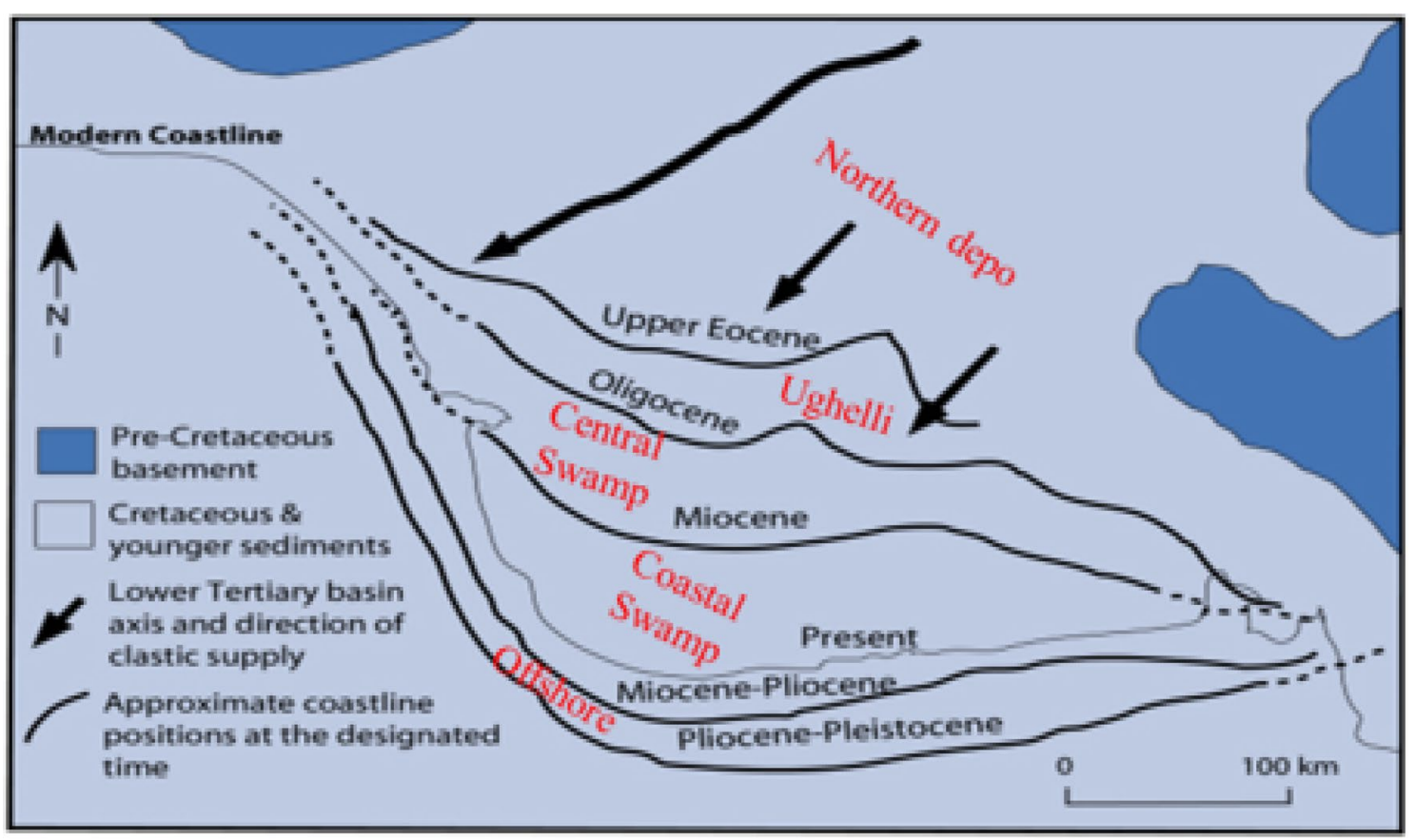

Fig. 2 Depobelts and direction of sediment deposition in Niger delta (Tuttle et al. 1999)

(a) The three regional formations of Niger Delta

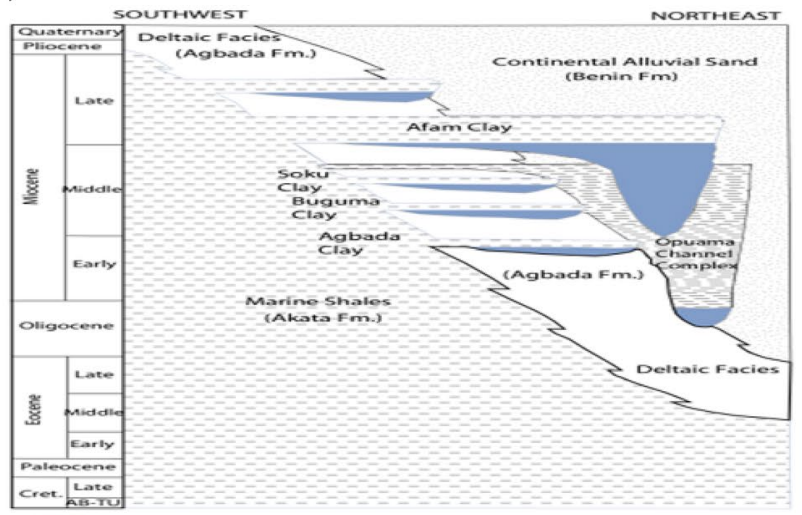

(b) Gravity tectonics of Niger Delta Continental Margin

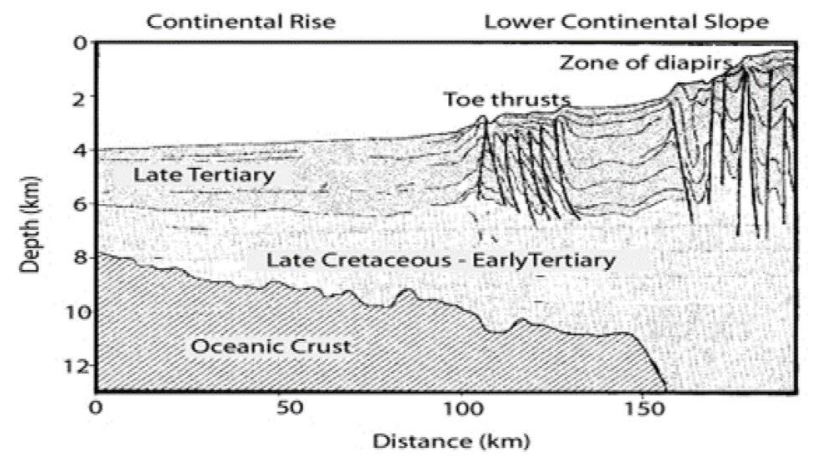

Fig. 3 The Niger delta formations and gravity tectonics (Tuttle et al. 1999)

The Tertiary Niger delta clastic sedimentary sequence is divided into three formations: Benin, Agbada (the reservoir rock) and Akata (the source rock and reservoir in deep offshore) formations (Fig. 3a). The Niger delta province has been identified to have only one petroleum system referred to as the Tertiary Niger delta (Akata-Agbada) petroleum system (Tuttle et al. 1999). The structural and stratigraphic complexities of distal delta province have been influenced by global plate tectonics and later by internal gravity tectonics in the Late Cretaceous to Tertiary. This has led to the formation of both structural and stratigraphic features capable of trapping hydrocarbons in the delta (Fig. 3b).

\section{Methodology}

The data used in this study include well logs from wells 14, 15 and 16, check shot data and 3D seismic volume (Fig. 4). The seismic data are a post-stack time migrated (PSTM) volume having 960 inlines and 443 crosslines, covering an area of about $266.4 \mathrm{sqkm}$. The quality of the data is good for the area of interest (target reservoir zone). 
Fig. 4 Base map showing well locations in MUN field

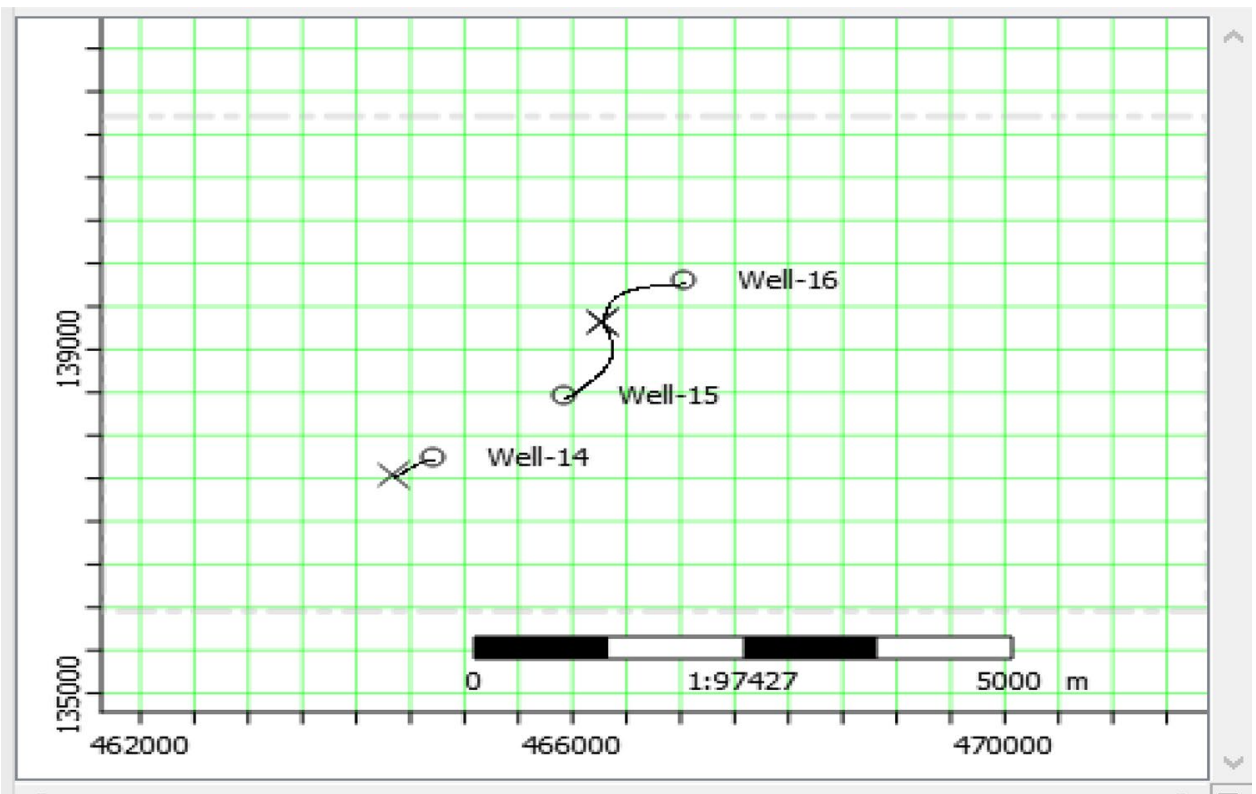

Standard processes of loading data to software (Petrel and HR) and data quality checks were performed. The methodology used to achieve our aim involved well log analysis, correlation, seismic to well tie, seismic amplitude attribute extraction and spectral decomposition of the seismic volume.

The conventional petrophysical methods were used to discriminate lithologies into sand and shale formations as well as characterise pore fluids at the wellbore using gamma-ray (GR) and resistivity (RT) $\log$, respectively. Delineated reservoir sands were correlated across the three wells for continuity and the effect of faulting in the neighbourhood of the wells. Subsequently, seismic to well tie was carried out to establish the well markers on the seismic data (Fig. 5).

Mapping and interpreting faults and seismic horizons on the seismic section were done after the seismic-to-well tie. Several horizons were mapped, and for this study, seismic $\mathrm{H} 4$ horizon was considered for analysis (Hampson and Russell 2012). Amplitude-related seismic attributes (Envelop, RMS and Sweetness) were extracted from the horizon to identify and map hydrocarbon zones. Prior to spectral decomposition, the amplitude-frequency analysis was done on the seismic dataset to determine the dominant seismic frequency and the frequency intervals to be adopted in creating data slices. Frequency volume was then generated using continuous wavelet transform (CWT) spectral decomposition method (Sinha et al. 2005), from which spectral (frequency) attribute slices were extracted along H4 horizon for subsequent analysis.

\section{Presentation of results}

Well log analysis discriminated reservoir sands from shale as well as characterise fluids using gamma-ray (GR) and resistivity (RT) logs in each of the wells. GR values were lower in reservoir sand lithofacies than shale while RT values were lower in shales than sands. This way hydrocarbonsaturated reservoir sands (sands 1 to 7 ) were discriminated from non-reservoir sands. The delineated sand tops were correlated across the wells, and result shows that the sand tops lie at different depths, suggesting probable faulting that may have caused the displacement of adjacent beds in each well (Fig. 6).

Fault interpretation from the seismic data show both synthetic and antithetic normal growth faults characteristic of the Niger delta, which seems to agree with the result of the well correlation in the study (Fig. 7).

Time structure map along seismic $\mathrm{H} 4$ horizon shows that the topography dips towards the southwest (Fig. 8). Major growth faults trend NW-SE in the northeast and southwest, respectively, perpendicular to the topographic gradient. The wells lie in moderate times (average elevation) flanked by low and high times and bounded by the growth faults. The low and high times correspond to valleys and hills, respectively. The geometry and disposition of the structures in place suggest favourable traps that could confine and accommodate hydrocarbons.

The seismic amplitude attributes (Envelop, RMS and Sweetness) extracted along H4 horizon show similar amplitude characteristics with varying resolutions (Fig. 9). Highamplitude anomalies exhibiting the signature of a channel sand saturated with hydrocarbons were mapped in each 

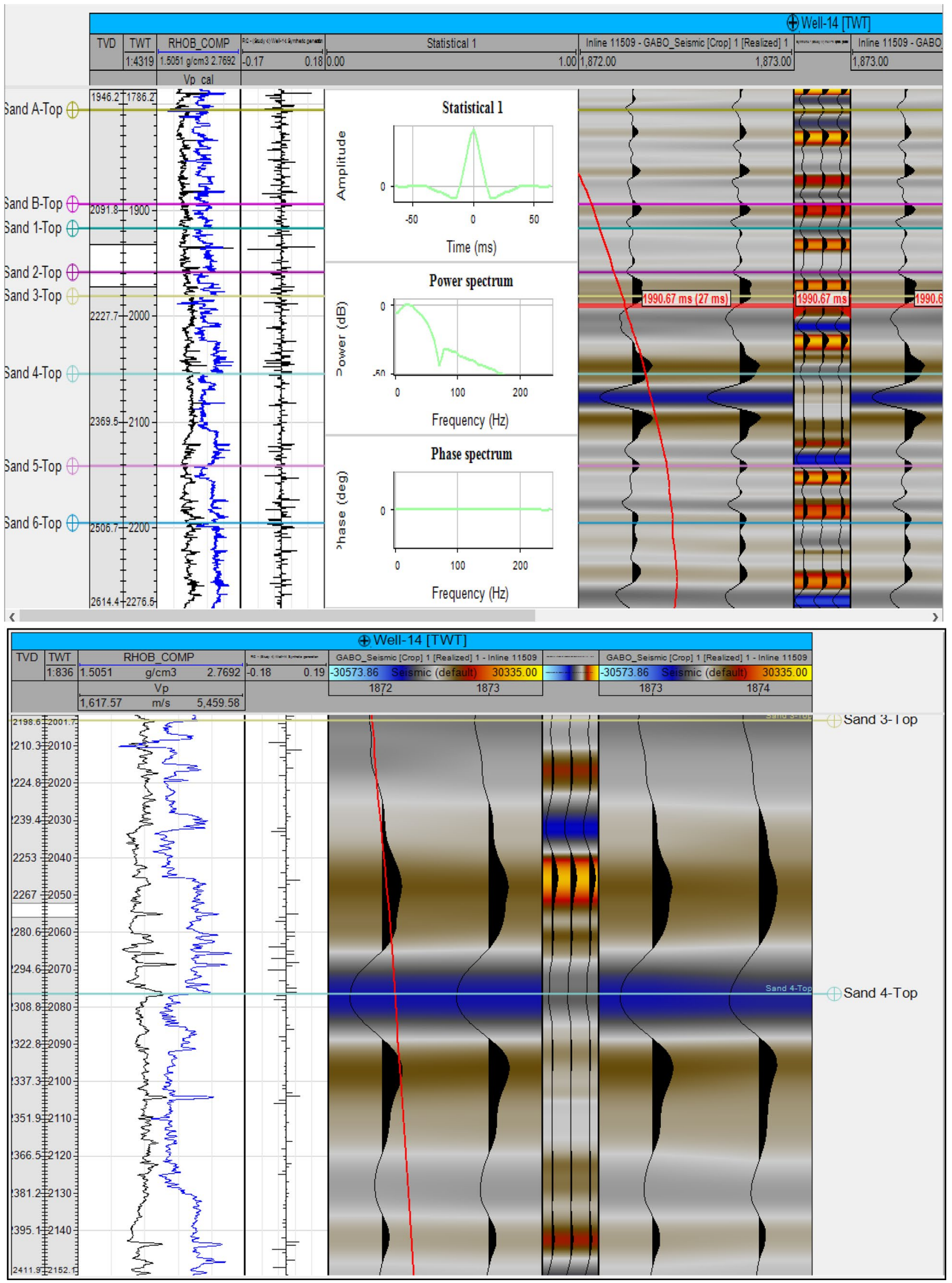

Fig. 5 Seismic to well tie (well 14) 
attribute map (Hart 2008; Okoch and Atakpo 2017). The wells are located on these high-amplitude anomalies in each map. Sweetness attribute appears more robust with brighter amplitudes than the RMS and envelop attributes. Amplitude brightening outside the well locations to the northeast of the channel is considered a by-passed prospect.

The amplitude-frequency analysis of the seismic data shows a broad maximum between 15 and $35 \mathrm{~Hz}$, with a characteristic dominant frequency at $25 \mathrm{~Hz}$ (Fig. 10). This result indicates that the frequency slices could be generated at $5 \mathrm{~Hz}$ frequency intervals to a maximum of $60 \mathrm{~Hz}$ and hydrocarbon-saturated channel sand imaged adequately at the $25 \mathrm{~Hz}$ dominant frequency band.

Subsequently, spectral (frequency) attribute slices of 5 to $60 \mathrm{~Hz}$ were extracted after spectral decomposition from the seismic data along seismic $\mathrm{H} 4$ horizon and analysed. Anomalous high-amplitude low-frequency zone (dark) was mapped between 15 and $35 \mathrm{~Hz}$ attribute slices exhibiting the depositional signature of a reservoir sand channel and visibly bounded by major growth faults to the southwest and northeast of the maps (Fig. 11a). Maximum amplitude low-frequency anomaly was mapped at $25 \mathrm{~Hz}$ attribute slice (Fig. 11b). Above and below this frequency band, the amplitude dims. The wells are located within the high-amplitude low-frequency anomalous zone associated with hydrocarbon saturation (Sinha et al. 2005; Chopra and Marfurt 2013). The high-amplitude low-frequency anomalous zone to the northeast of the channel is considered a by-passed prospect.

The results from sweetness and spectral attributes $(25 \mathrm{~Hz})$ slices were compared (Fig. 12). They complement each other in delineating the NE-SW trending reservoir sand channel, but the spectral attribute defines the channel better than sweetness attribute, providing finer and subtle details of structure and continuity within and beyond the channel.

Red-Green-Blue (RGB) spectral-based colour blending was adopted to optimise interpretation of the channel structure. Three frequencies of $5 \mathrm{~Hz}$ (low), $25 \mathrm{~Hz}$ (dominant) and $55 \mathrm{~Hz}$ (high) were assigned Red, Green and Blue colours, respectively, and colour blended (Fig. 13). From the result, it is evident that stratigraphic units within the channel structure have adequately been resolved and existing wells are visibly located on and along the channel sands.

The channel structure is characterised by amplitude brightening dominated mostly by the yellow colour, combination of the low and dominant frequencies to the southwest and purple color, combination of low and high frequencies to the northeast (east of the wells). These suggest hydrocarbon

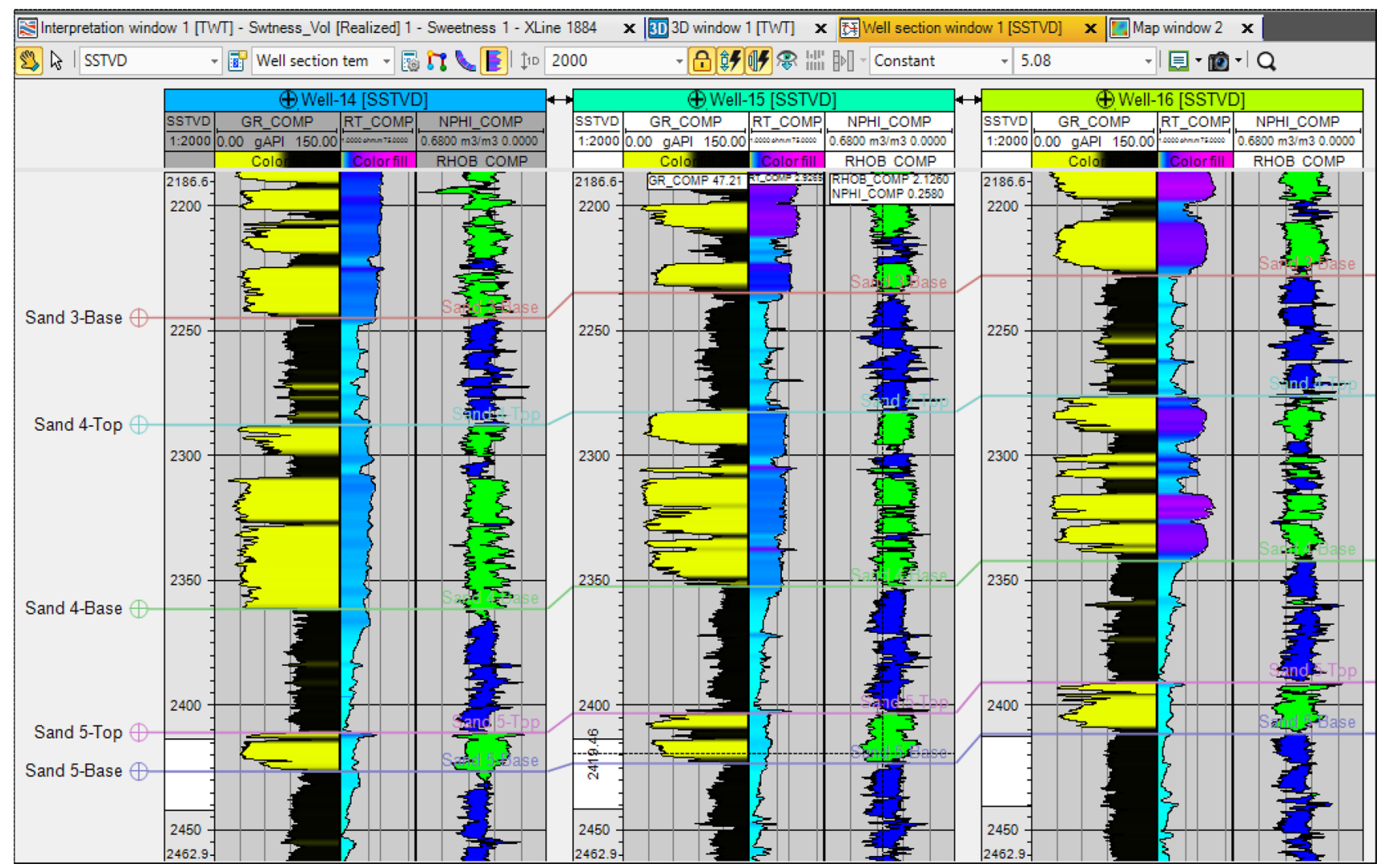

Fig. 6 Mapped reservoirs and well correlation 


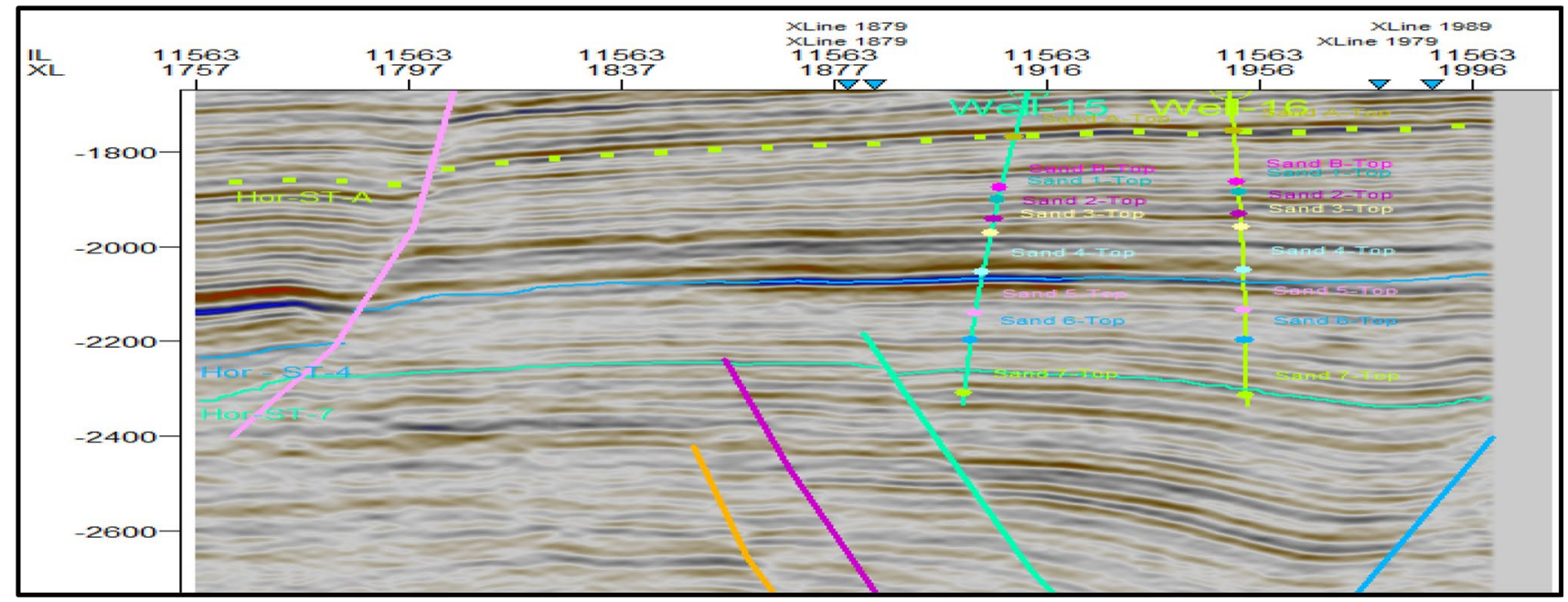

Fig. 7 Seismic cross section showing wells, faults and horizons

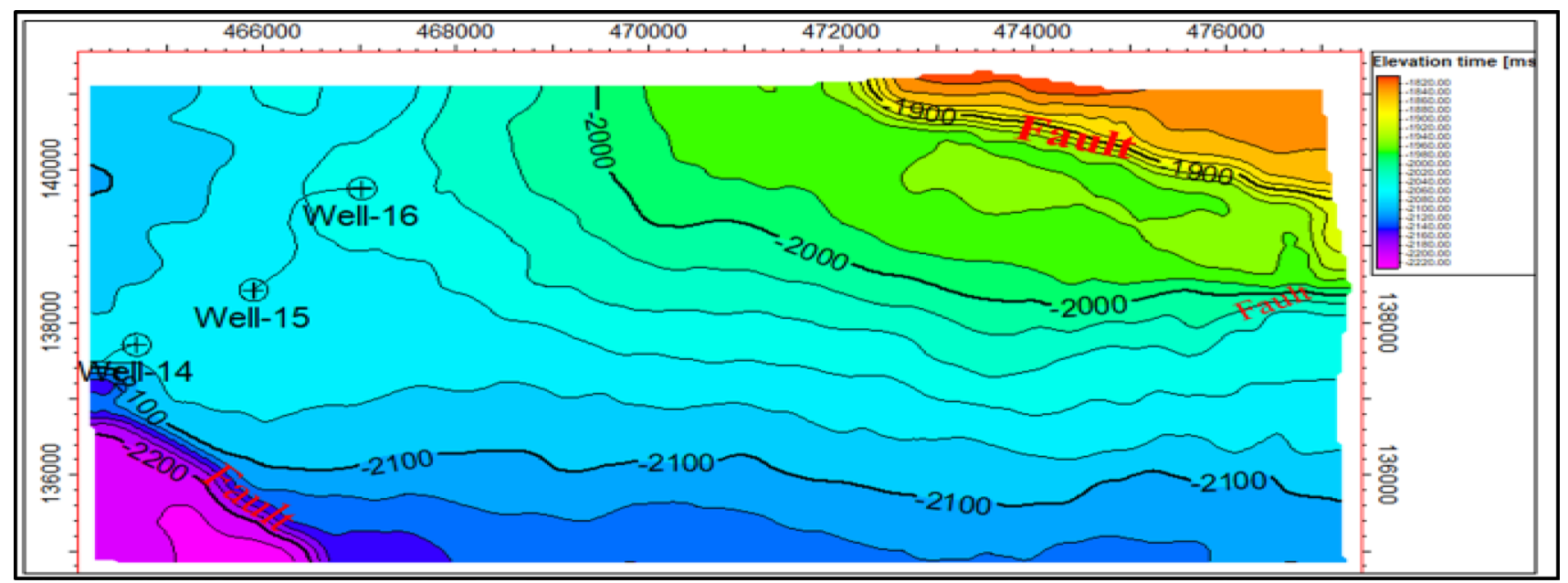

Fig. 8 Time structure map for H4 Horizon

presence, but thick and thin reservoir sands, respectively (Partyka et al. 1999; Chopra and Marfurt 2013). From the northeast, the channel structure broadens and thickens to the southwest with multiple channels.

\section{Discussion of results}

Petrophysical evaluation of the well logs delineated seven (7) reservoir sands (Sands 1 to 7) based on GR and RT signatures. The reservoirs were further analysed, and sand 4 reservoir was chosen for the present study based on its excellent petrophysical reservoir properties. This reservoir was correlated across the three wells and observed to be continuous with tops lying at different depths in each well, suggesting the effect of faulting (growth faults) in the neighbourhood of the wells and in the field capable of trapping hydrocarbons.

The seismic data were analysed for structure, and seismic $\mathrm{H} 4$ horizon was interpreted. The faults were both synthetic and antithetic normal faults (growth faults) characteristic of the Niger delta petroleum system (Obiekezie and Bassey 2015). Time structure map along seismic H4 horizon was characterised by a topography that dips to the southwest, with major growth faults trending NW-SW in the northeast and southwest, respectively, perpendicular to the topographic gradient. The geometry and disposition of the structures suggest favorable traps that could entrap hydrocarbons. The wells lie in moderate times (average elevation) flanked by low and high times and bounded by the growth 
Fig. 9 Amplitude attribute maps for H4 Horizon (a) Envelop attribute

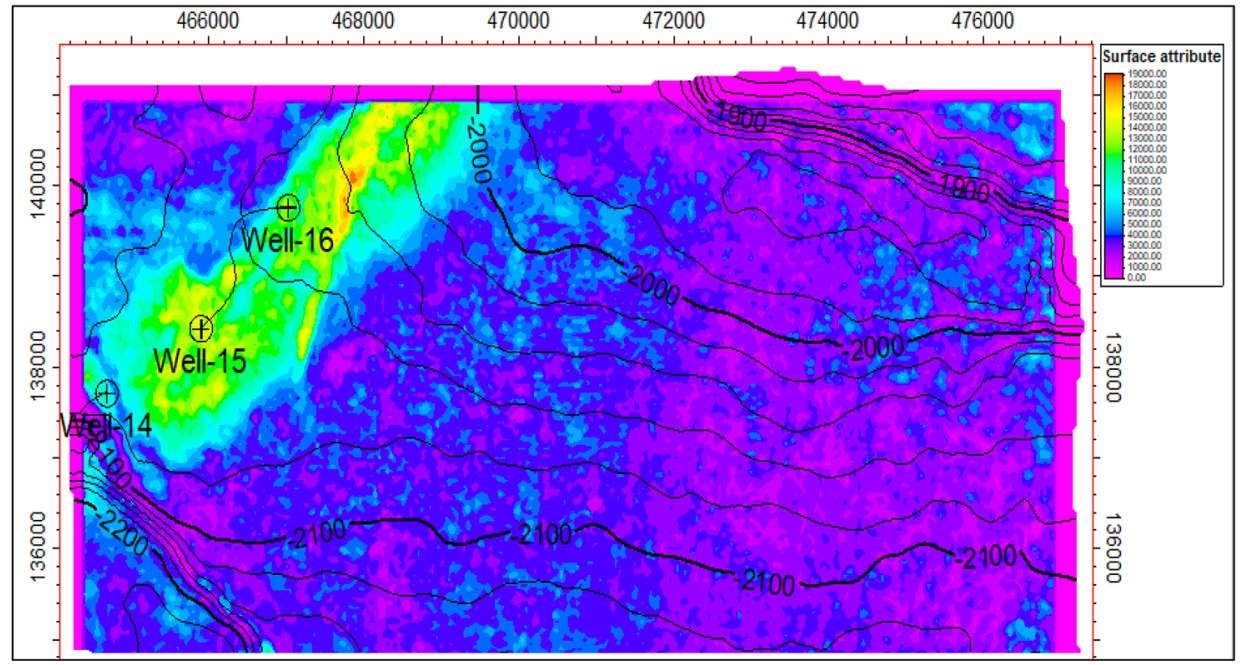

(b) RMS attribute

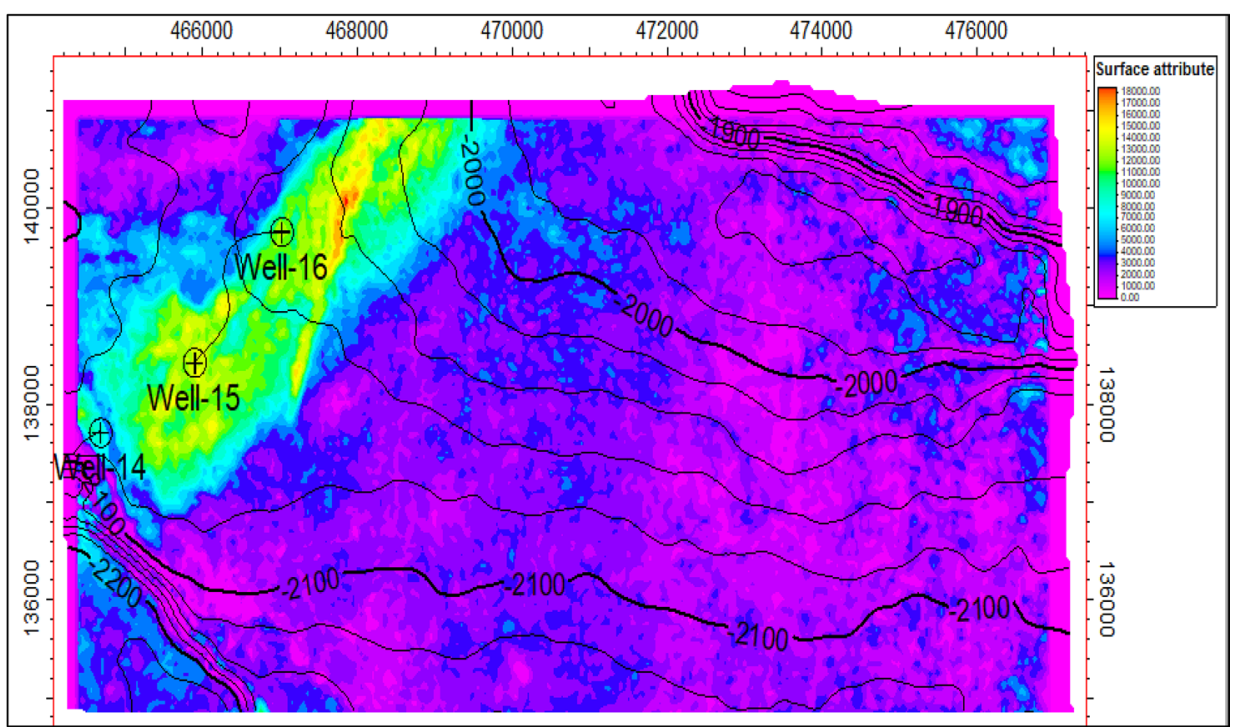

(c) Sweetness attribute

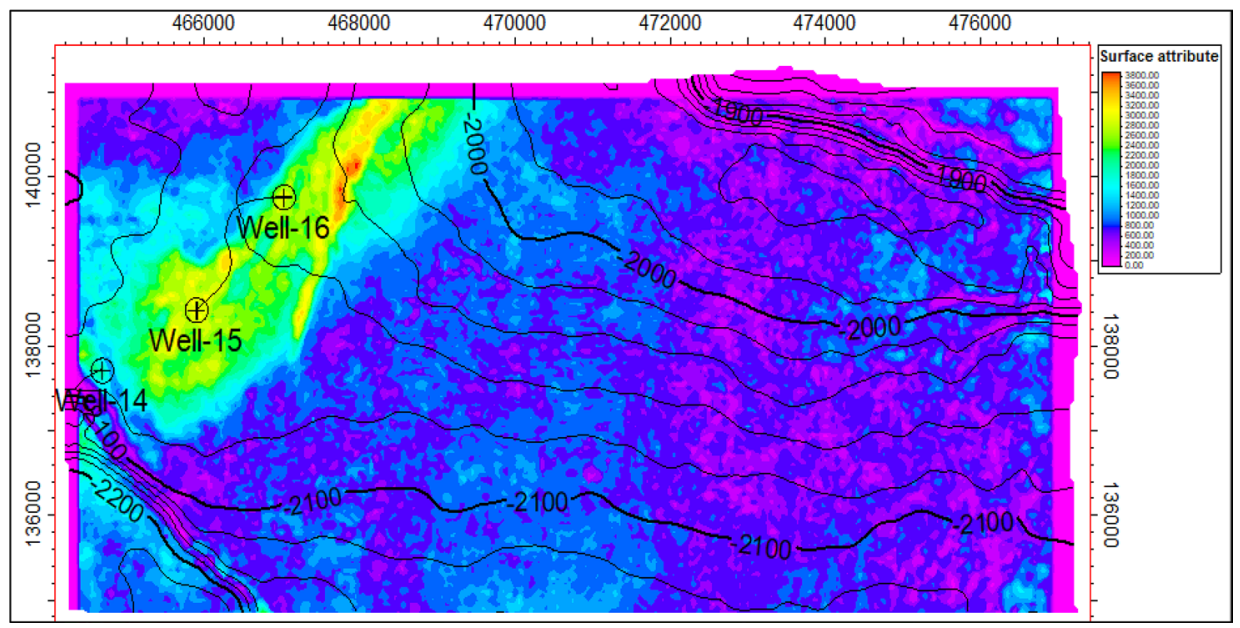




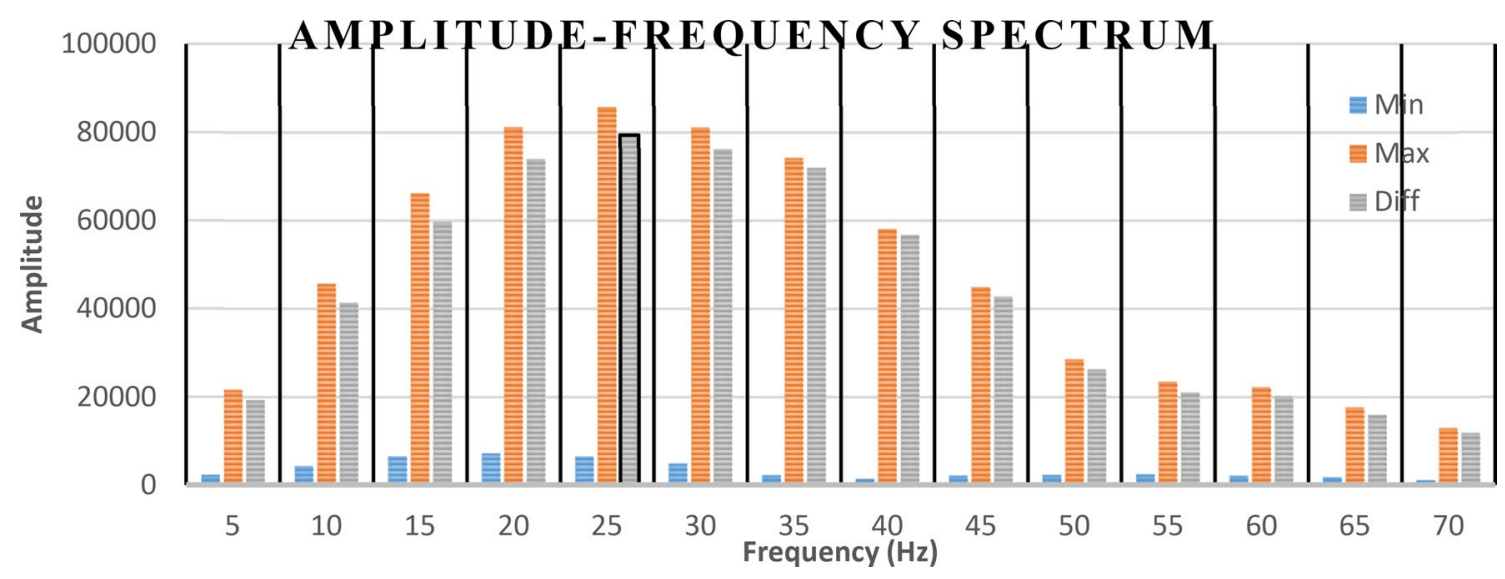

Fig. 10 Amplitude-frequency distribution analysis

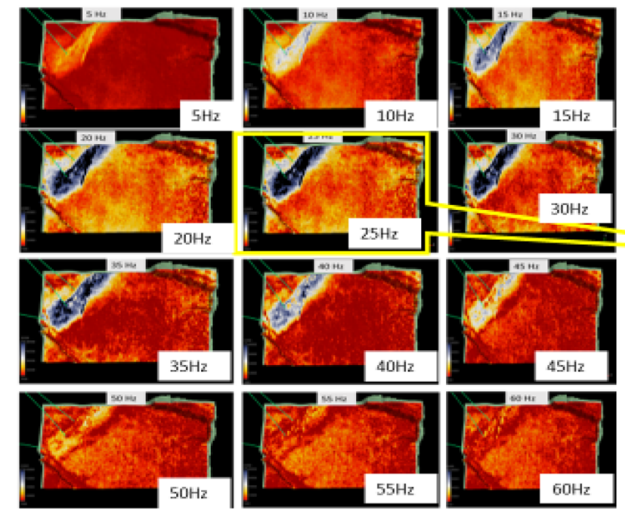

(a) Frequency attributes slices of $5-60 \mathrm{~Hz}$

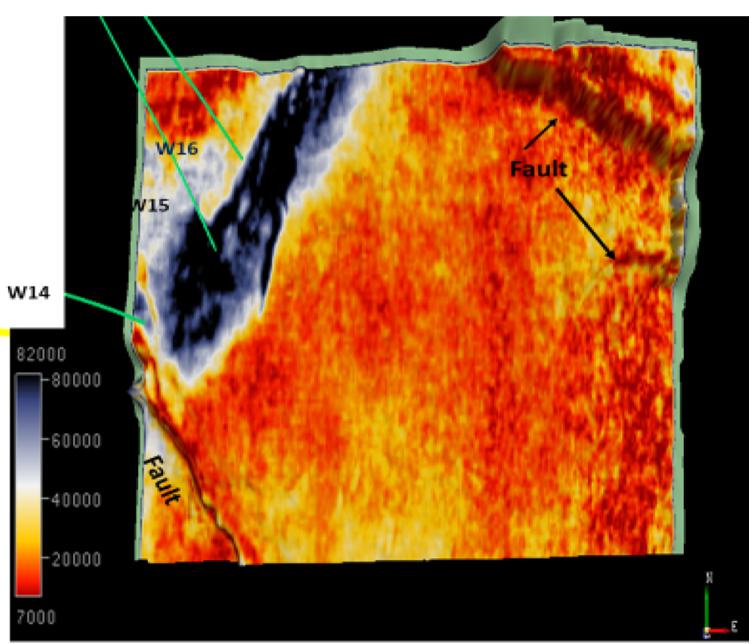

(b) $25 \mathrm{~Hz}$ Attribute slice

Fig. 11 Frequency slices showing different shades of anomalous dark zone

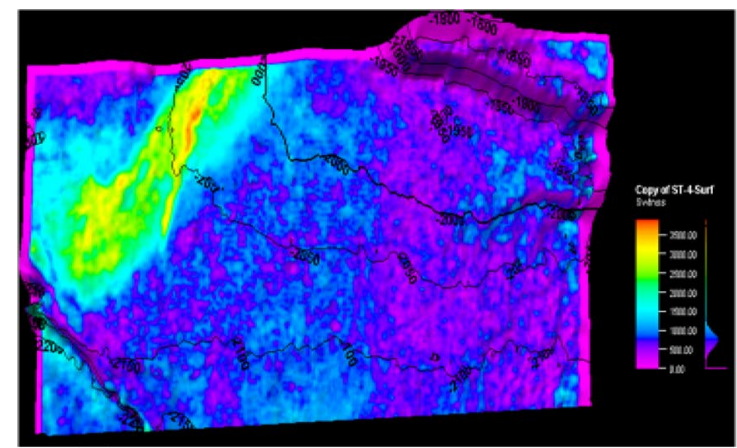

(a) Sweetness Attribute

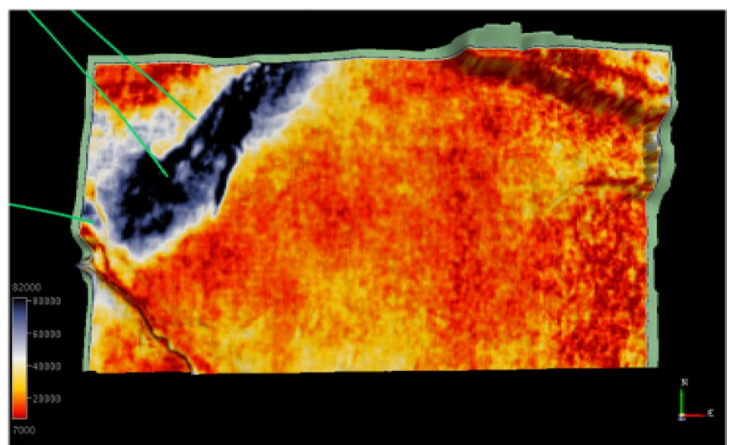

(b) Dominant frequency (25 Hz) Attribute

Fig. 12 Comparison of sweetness and spectral frequency $(25 \mathrm{~Hz})$ attribute slices 


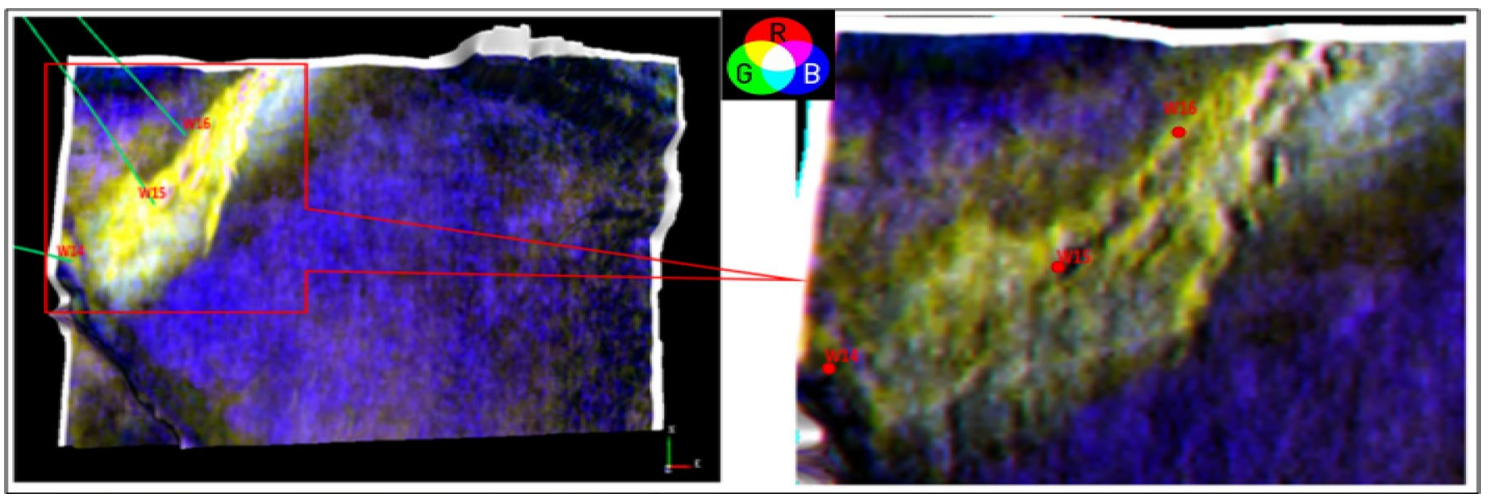

Fig. 13 RGB colour blended map

faults. The low and high times correspond to valleys and hills, respectively.

Seismic amplitude attributes (RMS, Envelop and Sweetness) along seismic $\mathrm{H} 4$ horizon show similar amplitude characteristics and structure but with varying resolutions. High-amplitude anomalies exhibiting the signature of a channel sand saturated with hydrocarbons were mapped in each attribute map (Hart 2008; Okoch and Atakpo 2017). The wells are located on this high-amplitude anomalies in each map. Sweetness attribute is the most robust with brighter amplitudes than the RMS and envelop attributes. This is due to the composite nature of sweetness attribute (a function of envelop and frequency) and its less sensitivity to noise compared to the other attributes. Thus, the lower the frequency, the higher the brightening associated with hydrocarbon sands and vice versa (Taner and Sheriff 1977). Amplitude brightening outside the well locations to the northeast of the channel structure is considered a by-passed prospect, which can be exploited in the field.

Spectral attribute slices were extracted along $\mathrm{H} 4$ horizon within the seismic bandwidth (5 to $60 \mathrm{~Hz}$ ) of the seismic data. The attribute slices delineated channel sand-like structure by high-amplitude low-frequency anomaly, characteristic of hydrocarbon saturation (Othman et al. 2016; Ehirim and Akpan 2017). The structure trends NE-SW, broadening towards the southwest and bounded by major growth faults similar to the result of the seismic amplitudes. The channel reservoir sands were imaged with increasing resolution between 15 and $35 \mathrm{~Hz}$ spectral band. The optimum image of the channel was obtained at $25 \mathrm{~Hz}$ spectral attribute which coincidentally is the dominant frequency of the seismic data.

Red-Green-Blue (RGB) spectral-based colour blending was subsequently adopted to optimise interpretation of the channel structure using three spectral bands of 5, 25 and $55 \mathrm{~Hz}$ with Red, Green and Blue colours, respectively. Stratigraphic units within the channel structure were adequately resolved and characterised by amplitude brightening at low and high frequencies, dominated mostly by the yellow and purple colours, respectively. This suggests hydrocarbon presence of saturating thick and thin reservoir sands, respectively (Partyka et al. 1999; Chopra and Marfurt 2013; Ehirim and Akpan 2017; Wei et al. 2019). The wells are located on and along the channel sands to the southwest. Spectral anomalies to the northeast of the channel is considered a bypassed prospect in agreement with the results of the seismic amplitudes.

\section{Conclusion}

Integration of seismic amplitude and spectral attribute analysis has successfully mapped, validated and characterised hydrocarbon-saturated channel sands by high-amplitude low-frequency anomaly. However, the spectral attributes in combination with RGB spectral-based attribute map show finer and subtle details of the channel structure and stratigraphy at the $25 \mathrm{~Hz}$ dominant frequency attribute slice, which hitherto, were not apparent in the seismic amplitude attributes.

The channel sands trend NE-SW, broadening towards SW and bounded by major growth faults to the northeast and southwest, respectively. It is thick to the southwest and thins to the northeast. Finally, by-passed hydrocarbon prospect was delineated to the northeast of the producing wells, and as such, infill wells can be drilled in these areas to recover hydrocarbons.

Acknowledgements We would like to thank Shell Petroleum Development Company of Nigeria for providing the 3D PSTM data for the study. Our thanks also go to World Bank, Africa Centre of Excellence in Oilfield Chemicals Research (ACE-CEFOR), UNIPORT; Jomo Kenyatta University of Agriculture and Technology (JKUAT) and RUFORUM for their support.

Open Access This article is licensed under a Creative Commons Attribution 4.0 International License, which permits use, sharing, adaptation, distribution and reproduction in any medium or format, as long as you give appropriate credit to the original author(s) and the source, 
provide a link to the Creative Commons licence, and indicate if changes were made. The images or other third party material in this article are included in the article's Creative Commons licence, unless indicated otherwise in a credit line to the material. If material is not included in the article's Creative Commons licence and your intended use is not permitted by statutory regulation or exceeds the permitted use, you will need to obtain permission directly from the copyright holder. To view a copy of this licence, visit http://creativecommons.org/licenses/by/4.0/.

\section{References}

Ahmad MN, Rowell P (2012) Application of spectral decomposition and seismic attributes to understand the structure and distribution of sand reservoirs within tertiary rift basins of Gulf of Thailand. Lead Edge 31:630-634

Aigbadon GO, Okoro AU, Una CO, Ocheli A (2017) Depositional facies model and reservoir characterisation of USANI field 1, Niger delta basin, Nigeria. Int J Adv Geosci 5(2):57-68. https:// doi.org/10.14419/ijag.v5i2.7720

Chopra S, Marfurt K (2013) Spectral decomposition's analytical value. AAPG Explorer Geophysical corner, pp 50-51

Doust H, Omatsola M (1990) Divergent and passive margin basins. Am Assoc Pet Geol Bull 48(1):201-238

Ehirim CN, Akpan AS (2017) Continuous wavelet transform based spectral decomposition of 3D seismic data for reservoir characterization in Oyi field, se Niger Delta. Am J Appl Sci 14(8):766-771

Evamy BO, Herembourne J, Kameline P, Knap WA, Molloy FA, Rowlands PH (1978) Hydrocarbon habitat of tertiary Niger Delta. Am Assoc Pet Geol Bull 62:1-39

Hampson DP, Russell B (2012) HRS-9 software suite for reservoir characterization. Calgary, Canada

Harilal SKB (2010) Pitfalls in seismics amplitude interpretation: lessons from Oligocene channel sandstones. Lead Edge 29(4):384-390

Hart BS (2008) Channel detection in 3-D seismic data using sweetness. AAPG Bull 92:733-742

Hilteman FJ (2001) Seismic amplitude interpretation. SEG/EAGE Distinguished Instructor Course No. 4

Houk R (1999) Estimating uncertainty in interpreting seismic indicators. Lead Edge 18:320-325
Klett TR, Ahlbrandt TS, Schmoker JW, Dolton JL (1978) Ranking of The world's oil and gas provinces by known petroleum volumes. Retrieved from http:// www.usgs.geological/report. 4th October, 2016.

Marfurt KJ, Kirlin RL (2001) Narrow-band spectral analysis and thinbed tuning. Geophysics 66:1274-1283

Obiekezie TN, Bassey EE (2015) Petrophysical analysis and volumetric estimation of Otu field, Niger Delta Nigeria, using 3D seismic and well log data. Phys Sci Int J 6(1):54-65, Article no. PSIJ.2015.033 ISSN: $2348-0130$

Okoch OO, Atakpo E (2017) Effect of hydrocarbon production on reflection amplitude propertis of reservoirs-a case of Kov Field, Niger Delta, Nigeria. Arab J Geosci 10:380. https://doi. org/10.1007/s12517-017-3171-1

Othman AAA, Fathy M, Maher A (2016) Use of spectral decomposition technique for delineation of channels for solar gas discovery, Offshore West Nile Delta, Egypt. Egypt J Pet 2016(25):45-51

Partyka G, Gridley J, Lopez J (1999) Interpretational applications of spectral decomposition in reservoir characterization. Lead Edge $18: 353-360$

Sinha SK, Routh PS, Anno PD, Philips C, Castagna JP (2005) Spectral decomposition of seismic data with continuous-wavelet transform. Geophysics 70:19-25. https://doi.org/10.1190/1.2127113

Taner MT, Sheriff RE (1977) Application of amplitude, frequency, and other attributes to stratigraphic and hydrocarbon determination. In: Payton CE (ed) Applications to hydrocarbon exploration. American Association of Petroleum Geologists Memoir, vol 26, pp 301-327

Tuttle MLW, Brownfield ME, Charpentier RR (1999) The Niger delta petroleum system: Niger Delta Province, Nigeria, Cameroon, and Equatorial Guinea, Africa. Tertiary Niger Delta (Akata-Agbada) Petroleum System (No. 701901). Open-File Report 99-50-H

Wei L, Dali Y, Wenfeng W, Wurong W, Shenghe W, Jian L, Depo C (2019) Fusing multiple frequency-decomposed seismic attributes with machine learning for thickness prediction and sedimentary facies interpretation in fuvial reservoirs. J Pet Sci Eng 177:1087-1102

Publisher's Note Springer Nature remains neutral with regard to jurisdictional claims in published maps and institutional affiliations. 